\title{
Uma história social da ciência e tecnologia
}

\author{
The social bistory of science \\ and technology
}

\author{
Moema de Rezende Vergara \\ Rua Gago Coutinho, 60/505 \\ 22221-070 Rio de Janeiro — RJ Brasil \\ moeres@uol.com.br
}

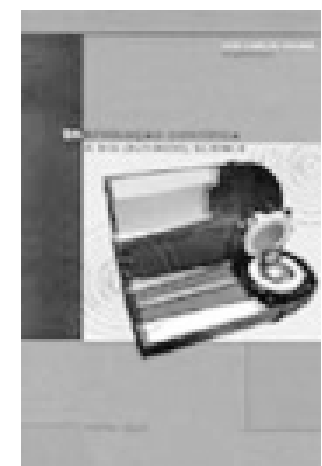

Luiz Carlos Soares Da revolução científica à Big (bussiness) science São Paulo, HUCITEC - EDUFF, 2001, 255p.
$\mathrm{T}$ radicionalmente, a história das ciências era um domínio de filósofos e epistemólogos ou de cientistas dedicados a registrar a memória de suas disciplinas. Canguilhem (1970, p. 10) conta-nos que Bernhard Sticker, diretor do Instituto de História da Ciência de Hamburgo, via uma contradição entre a destinação e o método desta disciplina, pois, segundo sua finalidade, ela deveria se localizar na Faculdade de Ciências, mas, se utilizado o critério metodológico, na Faculdade de Filosofia. Na prática, a maior parte dos historiadores cuidava de seus assuntos, ignorando o papel da ciência nos processos históricos. Numa perspectiva que procura romper com este estado de coisas, o livro organizado por Luiz Carlos Soares apresenta ao público brasileiro recentes pesquisas no campo da história social da ciência e da tecnologia. Nesta abordagem, representativa de um novo capítulo historiográfico da história da ciência, esta passa a ser vista como uma instituição social (Pestre, 1998, pp. 53-68), perdendo seu caráter de saber "desinteressado" acima do bem e do mal. Dessa forma, um diálogo mais intenso com as outras ciências sociais tornou-se premente para analisar as práticas sociais e discursivas presentes na atividade científica. Daí contar a coletânea com a presença não só de trabalhos de história social, mas também de filosofia e de história econômica.

A idéia de que a história das ciências é um "empreendimento de historiadores ausentes" abre o artigo de Carlos Alvarez Maia, 'A domesticação da história das ciências pelo sistema das ciências'. Maia relembra a "querela externalismo-internalismo" e como, neste contexto, A estrutura das revoluções científicas de Kuhn procurou ser uma possível resposta para este debate. Segundo o autor, Kuhn "domesticou" a história das ciências, elaborando uma imagem de ciência adequada aos interesses dos grupos envolvidos no sistema da atividade científica - a big bussiness science, termo que tenta dar conta da complexidade atual presente na prática científica, com suas devidas ramificações nas esferas da política e da economia. Como uma alternativa contrária a esta "domesticação", Maia cita os trabalhos de Steven Shapin representativos de uma história construtivista, com novas inclinações histórico-sociológicas. Shapin fez um resgate de uma tradição germânica das décadas de 1920 e 1930, marcada pelo conceito 
de "coletivo de pensamento" (Denkkollektiv) elaborado por Ludwik Fleck, que estaria associado ao de "estilo de pensamento" (Denkstil) presente na sociologia do conhecimento de Mannheim, tradição da qual o próprio Kuhn é seguidor. Contudo, pelo aprisionamento aos cânones das hard sciences, Kuhn afastou-se da perspectiva fleckiana que havia informado o seu olhar anteriormente. Ao submeter-se à pressão da época, talvez devido a uma aproximação com as ciências comportamentais, nos anos de 1958 e 1959, Kuhn substitui Denkkollektiv por "comunidade", desviando sua análise da raiz fleckiana, não indo além da síntese eclética que propôs como solução da querela externalista/internalista. Maia deixa assim evidente o recurso à historiografia como um instrumental analítico importante, para quem deseja uma história das ciências descomprometida com as narrativas palatáveis que a corporação dos cientistas estava acostumada a consumir e a aprovar.

Num outro recorte temporal, temos 'Entre utopia e pragmatismo: a história natural no iluminismo tardio' em que a natureza é apresentada como um tema central para a cultura européia na virada do século XVIII para o XIX. Este texto é o resultado da tese de doutoramento de Lorelai Kury, defendida na École des Hautes Études en Sciences Sociales, e recentemente publicada na França sob o título Histoire naturelle et voyages scientifiques (1780-1830). Kury nos apresenta duas idéias de natureza nos meios ilustrados franceses. Uma visão "utópica" que tecia muitas relações com o pensamento maravilhoso medieval e enfatizava as imagens de "paraísos de abundância", e outra, providencialista, caudatária dos termos da teologia natural dos primórdios do movimento ilustrado, em que os fenômenos e as leis da natureza são vistas como provas da benevolência de Deus para com os homens. A autora demonstra como, a partir da Revolução Francesa, construiu-se uma história natural não mais guiada pela mão da Providência Divina, mas portadora de um novo status: o de intérprete da natureza para a sociedade. Para os homens de ciência do final do século XVIII, os benefícios da natureza deveriam ser investigados por uma ciência "útil e desinteressada", cuja principal finalidade era proporcionar o bem-estar da sociedade. Para estes naturalistas, influenciados pelos ideais da Enciclopédia, não haveria uma oposição entre mundo natural e civilização, pois o controle da natureza era visto como o fundamento da civilização, e a vocação agrícola era um indicador do poder das nações "policiadas". Estas considerações tiveram grande repercussão no Brasil após a independência. A imagem de uma ciência da natureza como agente civilizador que traria prestígio à nação teve forte apelo junto aos idealizadores do Império brasileiro. Num outro texto em que Lorelai Kury (1998, p. 270) analisa a influência de Buffon, Cuvier e Saint-Hilaire sobre os naturalistas brasileiros do início do século XIX, ela afirma que "a natureza brasileira ocupou um lugar de destaque como elemento simbólico da especificidade nacional, as ciências naturais e a disseminação de suas teorias no seio da elite letrada adquiriram relevância para além das questões estritamente científicas". No caso brasileiro, a natureza desempenhou o papel de mito fundador da identidade nacional (Süssekind, 1990, p. 37). Se na 
literatura esse culto à natureza resultou numa vertente do romantismo, tingido pela cor local, às ciências da natureza se dirige uma constante demanda de subsídios para a construção de uma nação civilizada nos trópicos.

Em 'O nascimento da ciência moderna: os caminhos da revolução científica nos séculos XVI e XVII', Luiz Carlos Soares narra a revolução científica como um processo histórico lento e gradativo de articulação e cruzamento de tradições, concepções e práticas diversas de saber, surgidas ou retomadas nos séculos XVI e XVII. Esta trajetória propiciaria a emergência da ciência moderna, que terminaria por suplantar o saber mágico-hermético medieval. A partir deste processo, a atividade científica se transformou por completo, adotando desde então uma perspectiva racionalista, mecanicista, matematizada e experimental. O artigo de Luiz Carlos Soares tem o mérito de destacar a participação ibérica na revolução científica, tanto pela introdução dos algarismos indo-árabes na Europa, quanto pela valorização da experiência da navegação dos séculos XV e XVI. Esta experiência dos "homens práticos" da aventura marítima pode ter provocado a centelha que, no século seguinte, influenciaria o novo conceito de experimentação, não mais sensorial como o dos navegantes, mas aquele que Soares chama, seguindo Luís Filipe Barreto, de racionalista crítico-experiencial. Este último tornou-se a base da investigação e da descoberta científica e um novo critério de "verdade" foi obtido no âmbito da nascente ciência moderna. A inclusão lusa é de extrema importância para a produção de uma história das ciências no Brasil, pois, desde o século XIX, o nosso 'atraso' era constantemente explicado pelo fato de termos sido colônia de uma metrópole de exploradores e comerciantes sem tradição científica.

As relações entre o desenvolvimento científico e o tecnológico são investigadas no trabalho de Tamás Szmrecsányi - 'Esboços de história econômica da ciência e da tecnologia'. Apesar de a revolução industrial do século XVIII não ser herdeira direta da revolução científica do século XVII, a primeira desempenhou papel decisivo no progresso das ciências e das técnicas, na medida em que a partir da industrialização houve uma rápida difusão dos avanços técnicos, 'contaminando' a totalidade dos sistemas modernos de procedimentos produtivos. Tamás Szmrecsányi procura compreender as relações entre o progresso dos conhecimentos e o progresso econômico, uma distinção entre "as descobertas e invenções", de um lado, e as inovações tecnológicas propriamente ditas, de outro, lembrando que estas últimas são decisivas para o desenvolvimento econômico, através de seus mecanismos de indução e de difusão do progresso técnico. Contudo, a estreita relação entre o desenvolvimento econômico e as conquistas científicotecnológicas só será percebida no decorrer do século XIX, quando as atividades de pesquisa começam a se sistematizar e institucionalizar, dando lugar a uma especialização crescente nos diversos campos científicos. A atividade científica contemporânea será marcada pela integração dos conhecimentos científicos aos processos produtivos, trazendo vantagens competitivas decisivas tanto para o Estado quanto para as empresas. Pensando a necessidade de uma maior inter-relação 
entre a história e a história das ciências, cabe lembrar que foi a história econômica, nos anos 1930 na Inglaterra, que iniciou este diálogo, influenciada pela interpretação marxista da história, promovida por autores como J. D. Bernal, Joseph Needham ou o russo Boris Hessen. O materialismo histórico, aplicado à história da ciência, via esta última como sendo produzida e determinada pelas relações sociais e econômicas em que ocorre. Assim, "interpreta-se a ciência como uma forma de produção intelectual, ligada a preocupações econômicas, interesses de classe e valores ideológicos de períodos históricos e culturas particulares" (Martins, 2001, p. 23).

Finalmente, o filósofo Hilton Japiassú enfrenta a difícil tarefa de analisar 'O Projeto Masculino-Machista da Ciência Moderna'. O objetivo de Japiassú é mostrar a vinculação íntima do culto da racionalidade e da objetividade a um movimento de repressão dos sentimentos e da sensualidade, conseqüentemente, a uma tendência para estabelecer a inferioridade da inteligência feminina. Para o autor, a revolução científica foi uma ruptura dos saberes tradicionais das "mulheres, feiticeiras, bruxas e curandeiras". A leitura do artigo de Japiassú parece indicar uma idealização do período anterior ao surgimento da ciência moderna. Ele se pergunta por que os homens da época moderna tiveram necessidade de recorrer ao poder da racionalidade científica para reforçar sua dominação machista. Ora, se partirmos do pressuposto de que a ciência é uma instituição social, sua prática será marcada pelas formas de dominação e hierarquias estabelecidas na sociedade mais ampla. Entretanto, a análise destas condições que excluíram as mulheres de uma participação sistematizada dos processos de conhecimentos dominantes não foi o problema investigado por Japiassú. Parece-nos que atribuir ao conteúdo do conhecimento científico, mais especificamente à racionalidade, um poder de dominação e exclusão feminina nos deixa com mais perguntas do que respostas para a questão da predominância masculina na prática científica da Idade Moderna.

Lendo Da revolução científica à big (business) science, percebemos que a justificativa para a presença destes cinco artigos nesta coletânea está em terem sido apresentados no Laboratório de Epistemologia e História Social da Ciência e da Técnica da Universidade Federal Fluminense (UFF). Diferentemente das controvérsias vividas pelo Instituto de História da Ciência de Bernhard Sticker, o fato de o laboratório abrigar-se no Departamento de História abre algumas possibilidades para pensarmos sobre os rumos da história das ciências.

Desde o século XIX, podemos observar que a história da ciência tinha como uma de suas principais características cultuar os "grandes heróis". Poderia ser considerada como um dos últimos quartéis de uma história positivista que estudava a evolução histórica das teorias científicas aceitas, focalizando quase exclusivamente os "grandes pesquisadores" do passado e as idéias "vitoriosas". Esta história da ciência, já bastante criticada, adotava uma visão linear do progresso científico e pressupunha a existência de uma neutralidade e independência das ciências em relação ao meio social. Já não constitui novidade afirmar a necessidade de um diálogo entre a história e a 
história das ciências para romper com uma visão ingênua de que a ciência é o resultado do trabalho de alguns 'gênios' isolados. Contudo, gostaríamos de ponderar que este diálogo não pode ser de surdos, em que apenas um dos interlocutores tem direito à palavra. A troca entre estas disciplinas produz ganhos tanto para a história das ciências, ao perceber que a prática científica é uma atividade humana ligada a todas as outras atividades sociais, quanto para a análise dos processos históricos mais amplos, que começa a tomar consciência de que a ciência faz parte das relações culturais da mesma forma que, por exemplo, a filosofia e a religião.

\section{REFERÊNCIAS BIBLIOGRÁFICAS}

Canguilhem, Georges 1970

Kury, Lorelai 2001

Kury, Lorelai jul.-out. 1998

Martins, Roberto de Andrade 2001

Pestre, Dominique nov.-déc. 1998

Süssekind, Flora 1990
Études d'histoire et de philosophie des sciences. Paris, Librairie Philosophique J. Vrin.

Histoire naturelle et voyages scientifiques (1780-1830). Paris, L'Harmattan.

'Ciência e nação: romantismo e história natural na obra de Silva Maia'.

História, Ciências, Saúde-Manguinhos, vol. V, nº 2 .

'História e história da ciência: encontros e desencontros'. Em Actas do $1^{\circ}$ Congresso Luso-Brasileiro de História da Ciência e da Técnica. Évora, Universidade de Évora.

'Les sciences et l'histoire aujourd'hui'.

Le Débat, no 102.

O Brasil não é longe daqui. O narrador, a viagem. São Paulo, Companhia das Letras. 